\title{
Study and Simulation of the Density of the Incident Solar Flux on the Walls of a Building in Adrar, Algeria
}

\author{
A. Abdellatif Oudrane \\ Center University of Tissemsilt, \\ Tissemsilt, Algeria \\ abdellatif.habadat@gmail.com
}

\author{
B. Aour \\ Laboratory of Applied Biomechanics \\ and Biomaterials, Department of \\ Mechanical Engineering, ENP Oran, \\ Algeria \\ ben_aour@yahoo.fr
}

\author{
B. Zeghmati \\ Laboratory of Mathematics and \\ Physics, University of Perpignan Via \\ Domitia, France \\ zeghmatib@univ-perp.fr
}

\author{
X. Chesneau \\ Laboratory of Mathematics and Physics, University of \\ Perpignan Via Domitia, France \\ Chesneaux@univ-perp.fr
}

\author{
H. Messaoud \\ Research Unit in Renewable Energy in Saharan Medium \\ Adrar, Algeria \\ jhamouda@yahoo.fr
}

\begin{abstract}
In this work, we studied the effect of external climatic conditions on the evolution of the daily solar flux incident on the walls of a building located at Adrar region in the South of Algeria. This building is designed for heating or air conditioning applications. Numerical simulations allowed to compare the variation of the incident solar flux over a full day on the south, east, north and west walls of the building to the values of the solar flux on a horizontal wall (the outer ceiling). The horizontal global solar flux is calculated using a Gaussian sinusoidal function. The simulations were carried out in the case of a building located in a desert zone. The results of the numerical simulation showed the effect of the orientation of the building on the evolution of the incident daily solar flux.
\end{abstract}

Keywords-solar flux; Adrar; heating; simulation; desert zone

\section{INTRODUCTION}

The use of solar energy in sunny countries is an effective tool to compensate the energy lack and has also environmental interest because pollution has become a major problem [1]. Knowledge of the solar energy potential at a given site is an important parameter for designers of solar energy systems. The long-term evaluation of the performance of solar energy conversion systems is established using numerical simulation programs. In Algeria, the software for dimensioning photovoltaic and thermal installations claim, in most cases, integrated databases to calculate solar flux, based essentially on Capderou's model of the Solar Atlas of Algeria [2]. The optimal dimensioning and the best management of energy systems requires knowledge of meteorological conditions for which extensive studies are carried out in several regions of the world to assess and model the solar potential. The first step is to determine the different astronomical parameters, and more precisely the exact position of the sun during the year. First of all, it is necessary to define the two indispensable concepts in order to locate a place in the world: latitude and longitude [3].
Then, it seemed useful to us to study the theoretical modeling of the solar flux which allowed to carry out a comparative study between the different days in the season. The determination of the incident solar flux on the walls for different orientations of a building intended for heating in this desert region was studied by analyzing the effect of the climatic conditions of the region on the evolution of the solar flux. Results will be presented with a view to good dimensioning and optimum orientation of a building with a solar heating system. In this work, some fundamental notions of astronomy are presented which give information on the radiation received by the ground (diffuse, direct and global). The data required for the establishment of the solar energy balance (direct and diffuse flux calculations) are obtained by considering a sinusoidal variation of the ambient temperature and of the overall flux received on a horizontal wall and by considering the actual data of the maximum solar flux and the minimum and maximum temperatures recorded for the considered months on the Adrar site.

\section{EXPERIMENTAL DATA}

Currently, in Algeria, the measurement of solar radiation data is carried out in an instantaneous way on certain sites in Algeria. We chose the site of Adrar $\varphi=27^{\circ} 88^{\prime} \mathrm{N}$ and $\lambda=0^{\circ} 27^{\prime}$ $\mathrm{W}$ for this study. The choice of this site is based on the fact that Adrar is a city very rich in solar energy, given its average sunshine rate which reaches about $9963 \mathrm{Wh} / \mathrm{m} 2 \cdot \mathrm{j}$ [4]. For this reason, we have chosen this region in order to develop a building with a solar installation with maximum efficiency by playing on the climatic conditions. The data of the solar radiation (the mean ambient solar flux, the average ambient temperature) used were provided by the Adrar Renewable Energy Research Unit in the Saharian Medium (RERUSM). 


\section{MATHEMATICAL MODELING}

\section{A. Modeling of Geometric and Atmospheric Parameters}

\section{1) Hour Angle}

The hour angle $\omega$ (also denoted HA) of the sun is determined by the diurnal rotation of the earth around its axis. It is the measure of the arc of the solar trajectory between the sun and the meridian plane of the spot. Expressed in $\left(^{\circ}\right)$ angle, by the following expression $[5,6]$ :

$$
\omega=15 \times(T S V-12)
$$

where $T S V$ : represents the true solar time expressed in hours.

\section{2) Solar Declination}

The declination of the sun $\delta$ is the angle that the direction of the sun makes with the equatorial plane of the earth $[5,6]$. The declination varies from $-23^{\circ} 27^{\prime}$ at the winter solstice to $+23^{\circ} 27^{\prime}$ at the summer solstice and is zero at the equinoxes. Its value can be calculated by the formula of Cooper $(1969)[5,6]$ :

$$
\delta=23^{\circ}, 45 \times \sin \left(\frac{360}{365} \times(J+284)\right)
$$

where $J$ is the number of days elapsed since January $1^{\text {st }}$.

\section{3) Height of the Sun}

It is the angle $(h)$ formed by the horizontal plane at the place of observation and the direction of the sun. It is given by the relation $[5,7]$ :

$$
\sin (h)=\sin (\phi) \times \sin (\delta)+\cos (\phi) \times \cos (\delta) \times \cos (\omega)
$$

where $\varphi$ is the latitude of the place in decimal degrees, $\delta$ the sun declination in degrees and $\omega$ the hour angle of the sun in degrees. From the height $(h)$, we can deduce the hours of sunrise and sunset. We find, by making $h=0$ [8]:

$$
\cos \left(\omega_{0}\right)=-\operatorname{tg}(\phi) \times \operatorname{tg}(\delta)
$$

The astronomical duration of the day is obtained just as easily by making [8]:

$$
D_{0}=\frac{2}{15} \times \operatorname{Arccos}(-\operatorname{tg}(\phi) \times \operatorname{tg}(\delta))
$$

\section{4) Azimuth of the Sun}

It is the angle $a$ between the meridian of the place and the vertical plane passing through the sun. Knowledge of the azimuth is essential for the calculation of the incidence angle of the rays on a non-horizontal surface. The origin of the azimuths corresponds to the direction of the South in the northern hemisphere. The azimuth angle is positively counted towards the west. The azimuth is related to the hour angle, height and declination by the relationship [9]:

$$
\sin (a)=\frac{\cos (\delta) \times \sin (\omega)}{\cos (h)}
$$

\section{5) Time Equation}

To calculate the height of the sun and its azimuth, the time equation is necessary. The solar noon is the moment when the sun is at its maximum height. At this moment, it is positioned in the South or North direction, depending on whether it is in the northern or southern hemisphere. The solar noon differs from the local noon. This difference is called the time equation, it varies as a function of day and longitude and is given by the following expression [10]:

$$
\begin{array}{r}
E t=9,87 \times \sin \left(720 \times\left(\frac{J-81}{365}\right)\right)-7,53 \times \\
\cos \left(360 \times\left(\frac{J-81}{365}\right)\right)-1,5 \times \sin \left(360 \times\left(\frac{J-81}{365}\right)\right)
\end{array}
$$

\section{6) Real Solar Time}

It is the solar time local corrected of the time equation. Universal astronomical data related to the eccentricity of the orbit of the earth around the sun [10]:

$$
T S V=T L G-D E H+\left(\frac{E t}{60}\right)+\left(\frac{\lambda}{15}\right)
$$

where $D E H$ is the time difference, equal to $1 \mathrm{~h}$ for Algeria and $T L G$ : the local time in hours.

\section{B. Modeling Incident Solar Radiation on Any Plane for a Clear Sky}

1) Angle of Incidence

In solar applications the question is therefore to calculate the angle between a ray arriving directly from the sun and the normal at any plane. The orientation of the plane is defined by [11] its inclination $(\beta)$ which is angle that the plane makes with the horizontal and its azimuth $(\gamma)$. The angle of incidence $(\theta)$ is the angle between the direction of the sun and the normal of the plane and is determined by the knowledge of the direction cosines of the incident ray and the normal. In hourly coordinates [11]:

$$
\begin{aligned}
\cos (\theta)= & \sin (\delta) \times \sin (\phi) \times \cos (\beta)-\sin (\delta) \times \cos (\phi) \times \\
& \sin (\beta) \times \cos (\gamma)+\cos (\delta) \times \cos (\phi) \times \cos (\beta) \\
& \times \cos (\omega)+\cos (\delta) \times \sin (\phi) \times \sin (\beta) \times \cos (\gamma) \\
& \times \cos (\omega)+\cos (\delta) \times \sin (\beta) \times \sin (\gamma) \times \sin (\omega)
\end{aligned}
$$

\section{2) Calculation of Radiation for Any Plane of Inclination}

a) Calculation for a Clear sky on a Horizontal Plane

The global radiation $(\mathrm{RGH})$ received by a horizontal plane is divided into two terms:

- $\quad$ Direct radiation $(I)$ where $(H I R B)$ (luminance corrected for atmospheric phenomena);

- $\quad$ The diffuse radiation $(D)$ where $(R D I F H)$ comes from the whole celestial vault.

We will therefore have on a horizontal plane $[8,12]$ :

$G_{h}=I \times \sin (h)+D_{h}=I_{h}+D_{h}$ 
b) Diffuse Radiation for a Horizontal Plane

The diffuse radiation for a horizontal surface is given by the expression [7]:

$$
\begin{aligned}
& D_{h}=R D I F H=120 \times \Gamma \times \operatorname{Exp}\left(\frac{-1}{0.4511+\sin (h)}\right) \\
& \Gamma=0.796-0.01 \times \sin \left(\frac{360}{365} \times(J+284)\right)
\end{aligned}
$$

where $\Gamma$ is the nebulosity.

c) Radiation Calculation for an Inclined Plane

In practice, the global solar radiation on an inclined plane is expressed by the following form $[13,14]$ :

$$
G_{i}=I_{h} \cdot R_{b}+D_{h} \cdot\left(\frac{1+\cos (\beta)}{2}\right)+\rho \cdot G_{h} \cdot\left(\frac{1-\cos (\beta)}{2}\right)(13)
$$

where $\rho$ is the coefficient of reflection of the soil or albedo which varies according to the nature of the soil, and whose mean value is estimated to $\rho=0.25, R_{b}$ Is the geometric factor. The ratio between the incidence angle of solar radiation on the inclined wall and the cosine of the zenith angle $\cos (\theta)$ is:

$$
R_{b}=\frac{\cos (\theta)}{\cos \left(\theta_{z}\right)}
$$

and: $\cos \left(\theta_{z}\right)=\sin (\phi) \sin (\delta)+\cos (\phi) \cos (\delta) \cos (\omega)$

The algebraic relative error can be defined as the quotient of the absolute error at the real value [14]:

$$
\text { Err }=\left|\frac{G_{\text {Valued }}-G_{\text {Measured }}}{G_{\text {Measured }}}\right|
$$

where:

$G_{\text {Valued }}$ is the total solar flux density calculated in $\left(\mathrm{W} / \mathrm{m}^{2}\right)$

$G_{\text {Measured }}$ the total solar flux density measured by the radiometric station in $\left(\mathrm{W} / \mathrm{m}^{2}\right)$ and

Err the relative error.

\section{RESULTS AND DISCUSSION}

\section{A. Validation}

To test the validity of the models used to estimate the density of the solar flux, investigations were carried out on the global and direct solar flux density for a horizontal plane. The caliber models are used in the typical day of July 17, 2014 in order to validate these estimating models by making a comparison with the measured data. Figure 1 shows the calculated densities of the global (a) and direct (b) solar fluxes incident on a horizontal plane compared to those measured by the Adrar RERUSM radiometric station.

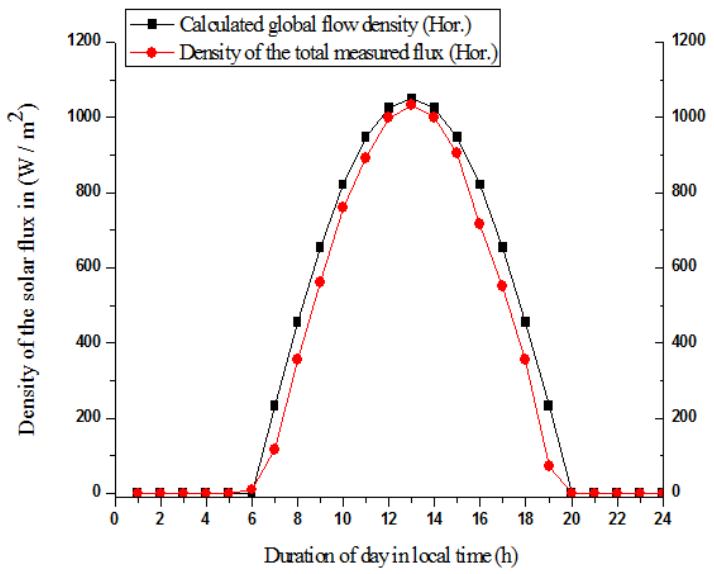

(a) Density of the total solar flux incident on a horizontal plane

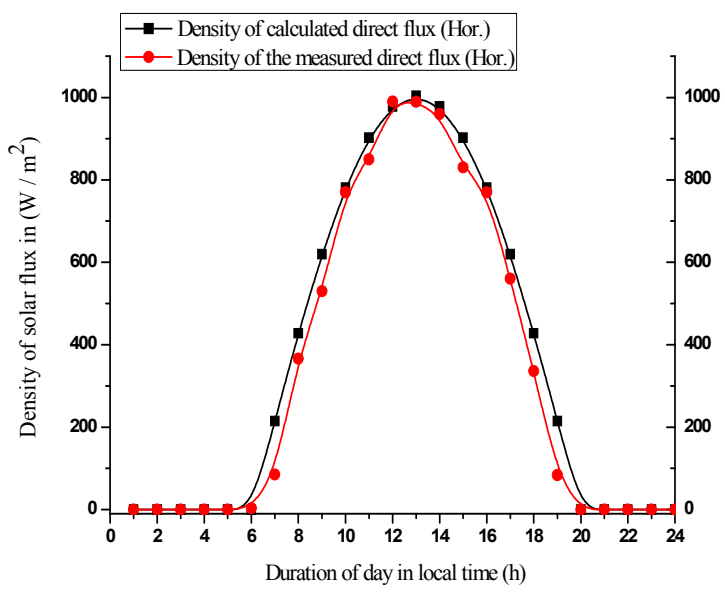

(b) Density of direct incident solar flux on a horizontal plane

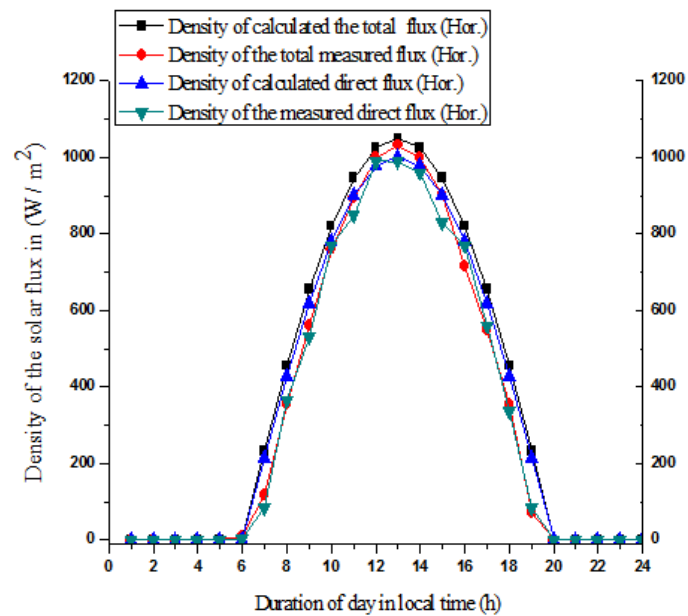

(c) Density of the total flux and direct flux on a horizontal plane

Fig. 1. Calculated and measured solar flux densities for a horizontal surface during the 17th of July 2014 in the region of Adrar. 
It can be observed that there is an acceptable agreement between the theoretical results and the experimental data, particularly in the middle of the day where the maximum relative difference does not exceed $1.8 \%$ for the case of the global solar flux and $1.5 \%$ for the case of the direct solar flux. Moreover, it can be also noted that the two types of flux have the same variation trend.

\section{B. Meteorological Conditions}

Figure 2 shows the evolution of the outside ambient temperature of the city of Adrar. The peak of the ambient temperature in June and July is recorded exactly at solar noon, whereas in August is recorded at 11 solar time. This difference between the two peaks is due to the fact that the duration of the day of August is smaller than that of June and July. Figures 3 and 4 represent the evolution of the density of the incident solar flux on the sunniest walls (East, West, South and Ceiling). During the diurnal period, it initially increases, passes through a maximum towards solar noon (Figure $3(a, b)$ ), decreases and finally drops to zero at night. But what differs from one wall to another is the maximum value and the corresponding instant, which vary according to the wall orientation. The flux is maximum in the morning on the east wall (Figure 3(a)), at noon on the South wall (Figure 4(a)) and in the afternoon on the west wall (Figure 3(b)). At midday, the incident solar flux is identical on both walls, but the maximum values differ from one month to another. For the south wall and the ceiling (Figure $4(a, b))$, the incident solar flux density has a symmetry with respect to noon TSV.

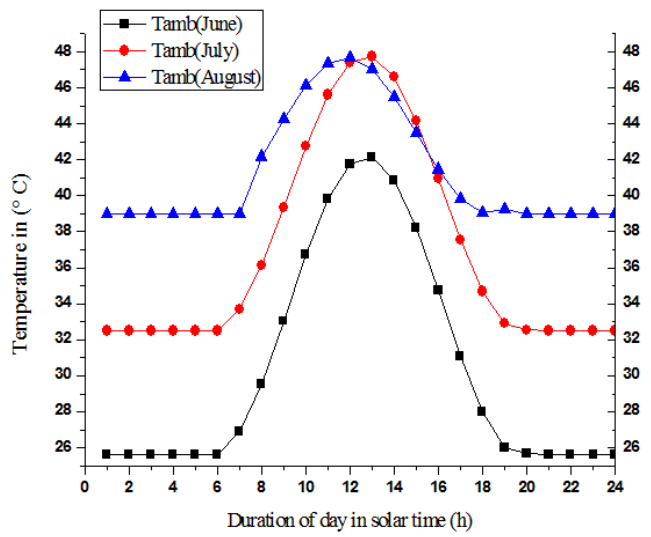

Fig. 2. Evolution of the outside ambient temperature for the typical day of the month (city of Adrar).

\section{Evolution of Solar Flux in July}

\section{a) Evolution of the Outside Ambient Temperature}

Figure 5 shows the evolution of the mean outside air temperature as a function of the hour for the month of July. The outside temperature of the building at solar noon is visibly greater than that of the periods before noon and afternoon and especially greater compared to the night period. This difference is due to the effect of the sun during a day in the summer season which allows the temperature increase to $47^{\circ} \mathrm{C}$ around noun. Figure 6 shows the instantaneous variations of the solar fluxes incident on the walls of the building for different orientations. This temporal evolution of the solar fluxes is calculated during the day of July 17, 2014. It is observed that the evolution of the incident solar flux on the walls is totally linked with the orientation of each wall of the habitable enclosure as well as with the position of the sun during the day.

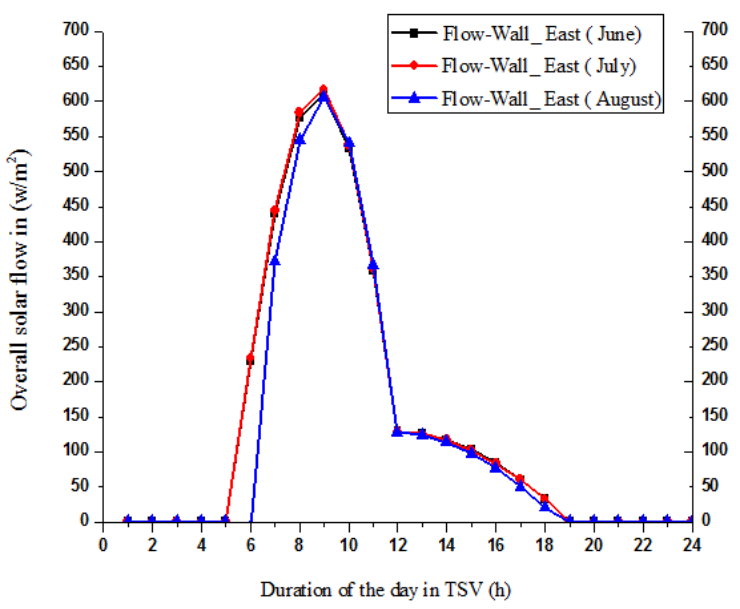

(a) East Wall

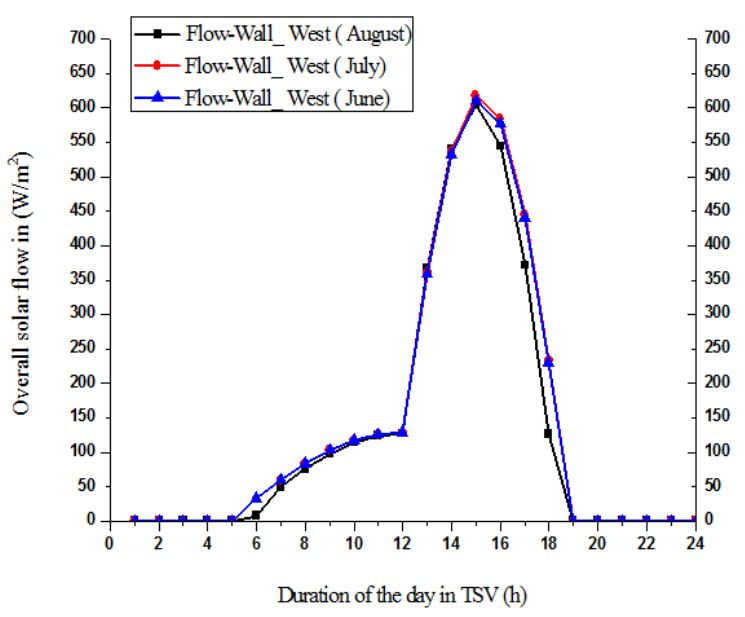

(b) West Wall

Fig. 3. Evolution of the incident solar flux density on the East and West walls.

b) Evolution of the Incident Solar Flux on the Walls of the Building

The solar flux in the walls of the building, during a 24-hour period is shown in Figure 6.

\section{CONCLUSION}

This work allows the study of evolution of the daily solar fluxes incident on the walls of a habitable enclosure located in Adrar according to the variation of the actual climatic conditions of this desert zone and also to the different possible wall orientations. The influence of meteorological conditions 
such as the external ambient temperature, the solar flux and the wall orientation on the evolution of the total horizontal and incident solar flux were studied and analyzed. The results have mainly shown that the outside temperature has a large variation according to the selected months. Moreover, it has been found that the orientation of the structure of the habitable enclosure must also be taken into account in order to optimize the capture of solar radiation. Thus, this orientation must be south-facing in an ideal way to have a maximum of $400 \mathrm{~W} / \mathrm{m}^{2}$ towards solar noon and a maximum of $650 \mathrm{~W} / \mathrm{m}^{2}$ before noon for an orientation towards the East and the same value in the afternoon for an orientation towards the west. However, the surrounding obstacles must be taken into account.

\section{ACKNOWLEDGMENT}

We would like to thank the Director of the UREMS of Adrar for the supply of climate data and the Ministry of Higher Education and Scientific Research of Algeria for the financing of the finalization project of the thesis of Mr. A. Oudrane.

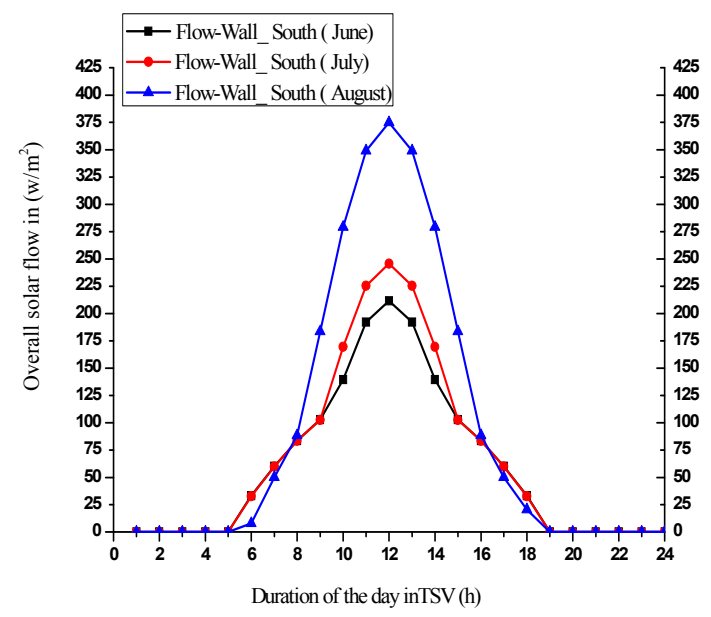

(a) South Wall

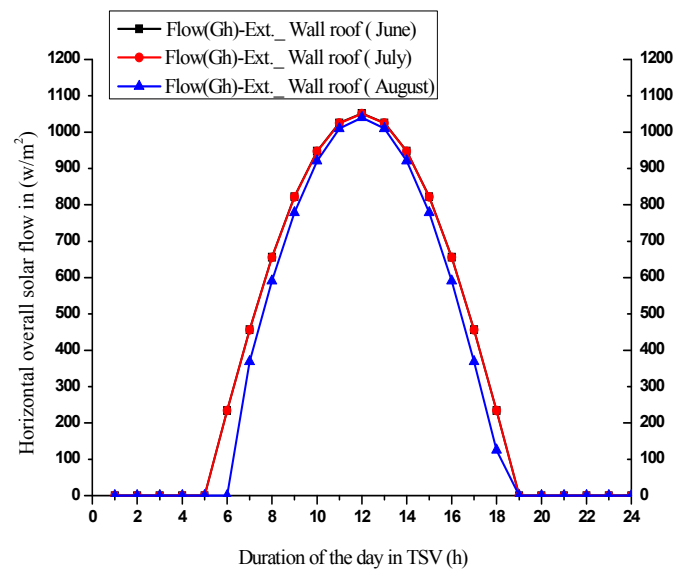

(b) External Wall Roof

Fig. 4. Evolution of the incident solar flux density on the South wall and the ceiling.

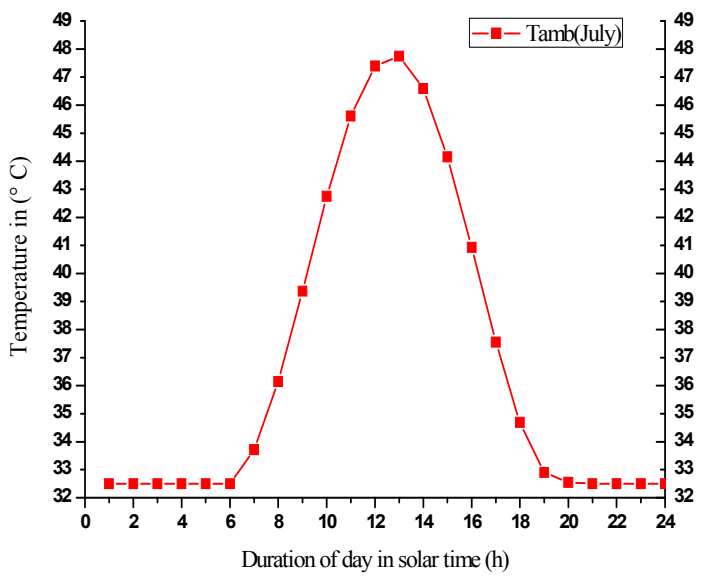

Fig. 5. Evolution of the mean outside air temperature as a function of time.

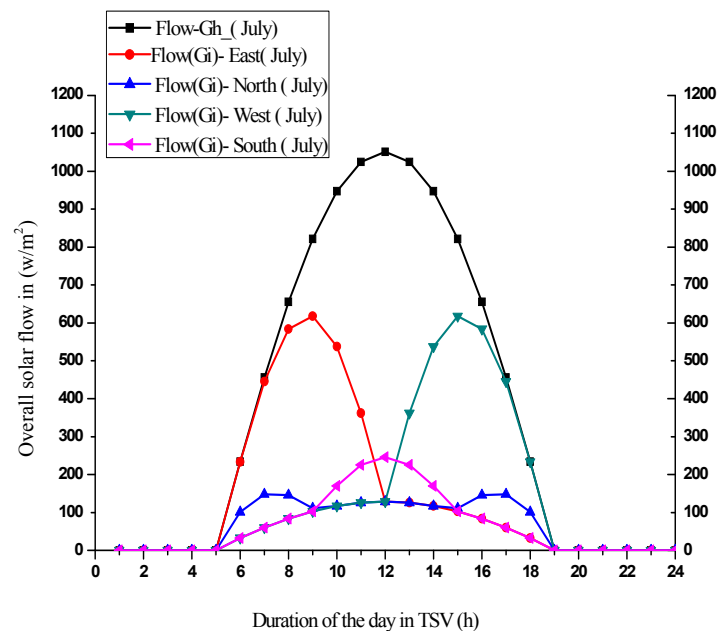

Fig. 6. Incident solar fluxes for different orientations during the 17th of July 2014 in the region of Adrar

\section{REFERENCES}

[1] M. Ghodbane, N. Moummi, B. Boumeddane, S. Largot, H. Berkane, "Study and numerical simulation of solar system for air heating", Journal of Fundamental and Applied Sciences, Vol. 08, No. 01, pp. 4160, 2016

[2] F. Yettou, A. Malek, M. Haddadi, A. Gama "Etude comparative de deux modeles de calcul du rayonnement solaire par ciel clair en Algerie", Revue des Energies Renouvelables Vol. 12, No. 2, pp. 331-346, 2009

[3] M. Hamdani, S. M. A. Bekkouce, T. Benouaz, M. K. Cherier, "Etude et modelisation du potentiel solaire adequat pour l'estimation deseclairements incidents a Ghardaia", Revue Internationale D'Heliotechnique, No. 43, pp. 8-13, 2011

[4] M. Capderou, Atlas solaire de l'Algerie, Tome 2, 1985

[5] R. J. Alain, Gisement solaire et transferts energetiques, Universite de Cergy-Pontoise, 2011

[6] Aghilas Brahimi, Etude de performances d'un capteur solaire plan a eau, MSc Thesis, University of Lorraine, 2016 
[7] Y. El Mghouchi, A. El Bouardi, Z. Choulli, T.Ajzoul "New model to estimate and evaluate the solar radiation", International Journal of Sustainable Built Environment, Vol. 3, No. 2, pp. 225-234, 2014

[8] L. Yuehua, J. Yingni, C. Xinxiao, "Evaluation of three models for calculating daily global solar radiation at Yushu, Tibet", IEEE International Conference on Consumer Electronics, Communications and Networks (CECNet), pp. 1252-1255, 2011

[9] K. Kabidi, Experimentation et modelisation du comportement energetique et thermique d'un sechoir solaire sous le climat de la region de Rabat, PhD Thesis, Universite Mohammed v - Agdal, 2014

[10] K. Kerkouche, F. Cherfa, A. Hadj Arab S. Bouchakour, K. Abdeladim, K. Bergheul "Evaluation de l'irradiation solaire globale sur une surface inclinee selon differents modeles pour le site de Bouzareah", Revue des Energies Renouvelables Vol. 16 No. 2, pp. 269-284, 2013

[11] F. Chabane, Modelisation des paramètres de conversion thermique de l'energie solaire, $\mathrm{PhD}$ Thesis, University of Biskra, 2015

[12] A. Kaddour, Modelisation et simulation d'un concentrateur parabolique solaire a moteur Stirling en vue d'un rendement optimal, PhD Thesis, University of Abou Bekr Belkaid, 2013

[13] A. Moummi, N. Hamani, N. Moummi, Z. Mokhttari, "Estimation du rayonnement solaire par deux approches semi empiriques dans le site de Biskra", 8th International Meeting on Energetical Physics, Algeria, 2006

[14] M.R Yaiche, S. M. A Bekkouche, "Estimation du rayonnement solaire global en Algerie pour differents types de ciel", Revue des Energies Renouvelables, Vol. 13, No. 4, pp. 683-695, 2010 